\title{
Pulmonary Functions are Impaired among Carpet Factory Workers: A
}

\section{Spirometric Evaluation}

Binaya SJB Rana, ' Dinesh Banstola, ' Narayan B Mahotra, 'Lava Shrestha, 'Matiram Pun'

'Department of Clinical Physiology, Maharaigunj Medical Campus, Institute of Medicine, Tribhuvan University, Nepal.

\begin{abstract}
Introduction: Carpet factory produces various types of dusts and workers occupationally get exposed to them continuously. It has adverse health effects and most notably to the pulmonary functions. Nepal is one of the carpet exporter developing countries and still does have many factories within Kathmandu valley. However, the health hazards especially the status of pulmonary function of carpet factory workers from Nepal has not been studied.
\end{abstract}

Methods: A cross-sectional comparative study was designed to recruit carpet factory workers and healthy controls to assess their pulmonary functions. A total of 118 subjects ( 59 males and 59 females) were recruited (60 carpet factory workers and 58 controls). Pulmonary function tests were carried out using Medical International Research Spirolab II portable spirometer.

Results: The carpet factory workers had significantly less $\mathrm{FEV}_{1}(90.37 \pm 16.6 \%$ vs. 103.89 $\pm 9.79 \%$, $\mathrm{p}<0.001)$, FVC $(87.78 \pm 15.48 \%$ vs. $102.81 \pm 8.41 \%, \mathrm{p}<0.001)$ and PEFR $(66.19 \pm 20.29 \%$ vs. $102.81 \pm$ $11.09 \%, \mathrm{p}<0.001)$ as compared to control group. Similarly the carpet factory workers had significantly higher $\mathrm{FEV}_{1} / \mathrm{FVC}$ ratio $(89.96 \pm 6.42 \%$ vs. $87.12 \pm 4.58 \%, \mathrm{p}=0.007)$ as compared to control.

Conclusions: Carpet industry dusts exposure adversely affects pulmonary functions among its workers. The findings significant increase in the $\mathrm{FEV}_{1} / \mathrm{FVC}$ ratio and decrease in $\mathrm{FEV}_{1}, \mathrm{FVC}$, and PEFR suggest that the effects are both restrictive and obstructive patterns of lung disease.

Keywords: carpet industry; lung function; occupational health; pollution; spirometry.

\section{INTRODUCTION}

Carpet is one of the exports of Nepal. The Carpet industry is primarily concentrated in the Kathmandu valley. The art of weaving is an old tradition in Nepal, especially in the mountainous regions of the country. The domestic carpet related weavings e.g. Radii, Pakhi, Bakkhu, Darhi are well-known Nepalese products produced in these regions using indigenous wool. Traditionally as well as industry-wise, carpet production involves long and continuous exposure of extraction, processing, weaving and final wrapping processes. During these steps, the workers are exposed to various dusts produced and chemicals used in the carpet production. ${ }^{1,2}$ The carpet industry particularly soared up in Nepal (especially Kathmandu valley) afterwards Tibetan refugee influx. This led to the development of export quality carpets commenced in the early sixties. The carpet has become an internationally recognized commercial commodity and remains one of the most important export products from Nepal. ${ }^{3}$ Prior to 1984 ,

Correspondence: Dr. Matiram Pun, Department of Clinical Physiology, Institute of Medicine, Tribhuvan University, Kathmandu, Nepal. Email: matiram@gmail.com, Phone : +977-9813021503. 
no machineries were used and it was all manual in the carpet production process. All are the sources of particulate emissions. This together with long hours of working makes the carpet industry a high risk occupation for developing various types of musculoskeletal disorders, ${ }^{4}$ respiratory disorders, injuries, eyesight problems, nerve disorders and skin problems. ${ }^{5-7}$ The poor environmental conditions coupled with unhygienic conditions have been found to be the reasons for developing such types of disorders. ${ }^{8-10}$ Till today many carpet industries either use similar technique or semiautomatic techniques to ensure high quality fleece wool is imported. Even if they use machines, there is fair-bit of manual work involved and exposure to the significant amount of dusts and pollution. The exposure can lead to various health hazards most notably lung functions of the employees. ${ }^{11,12}$

It is estimated that almost one-third of the global disease burden can be attributed to environmental risk factors. ${ }^{13,14}$ About four thousand deaths per annum are from asbestos and the remaining 8,000 deaths per annum are due to exposure to a wide range of hazardous substances resulting in cancer, chronic obstructive pulmonary diseases (COPD) ${ }^{15}$ and other serious lung diseases. ${ }^{16-18}$ Majority of the workers in developing countries are employed informally, therefore they have no written contract, no benefits other than wages and are excluded from social security schemes and thus putting them at a severe risk to their health as they are unable to pay health bill. ${ }^{19}$ The respiratory symptoms are common problems among carpet factory workers (20.0-41.8\%). ${ }^{19}$ The cotton dusts have adversely affect textile workers ${ }^{20}$ and the most important culprit seems inhalable dusts. ${ }^{21}$

Developing countries like Nepal, and other South Asian countries, are more prone toward workers' ill-health and environmental damages mainly due to unsatisfactory quality of work environment and health support. ${ }^{22}$ Carpet factory workers are also not aware about the health hazards of working in the carpet factory. Therefore, it is important to study the pulmonary function status of these groups of workers in our country, to determine the magnitude of respiratory problems among carpet factory workers and to compare their pulmonary function status with that of subjects not working in the carpet factory. Hence, this study was designed to compare the spirometric parameters of pulmonary function of individuals working in carpet factories with the control group (who were not exposed to carpet factory particulates).

\section{METHODS}

A cross-sectional comparative study was designed to recruit workers (working more than a year) of Carpet Industry in Kathmandu and a control group healthy, age and sex matched subjects. A total of 118 (60 carpet factory workers and 58 controls), non-smoker and not contra-indicated for spirometry, subjects with the age of 18 to 45 years were recruited.

The subjects were counseled about the procedure and demonstrated. Then Spirometry was performed, using MIR Spirolab II (Medical International Research, Via del Maggiolino, 12500155 Roma, (taly) ${ }^{23}$ in all subjects in the sitting position by open circuit method. The test was done at least three times for each participant until the recorded spirogram fulfilled the American Thoracic Society's acceptability and repeatability criteria ${ }^{24}$ up to a maximum of eight attempts and the best values were considered for the study. ${ }^{25}$

The data were expressed as mean \pm standard deviation (SD). Microsoft Excel 2007 was used for data entry and Statistical Package for Social Sciences (SPSS, version 16) was used for analysis of collected data. Independent sample t-test was applied wherever it was necessary. Value for probability less than $0.05(p<0.05)$ at $95 \%$ confidence interval was considered statistically significant. The ethical approval was obtained from the Institutional Review Board (IRB) of the Institute of Medicine. All the subjects provided informed-written consent.

\section{RESULTS}

A total of 118 subjects were recruited for the study. Among them, 60 (50.8\%) were carpet factory workers while 58 (49.2\%) were healthy controls as shown Figure 1. On a sex-wise distribution, 59 (50\%) were males and $59(50 \%)$ were females (Figure 2).

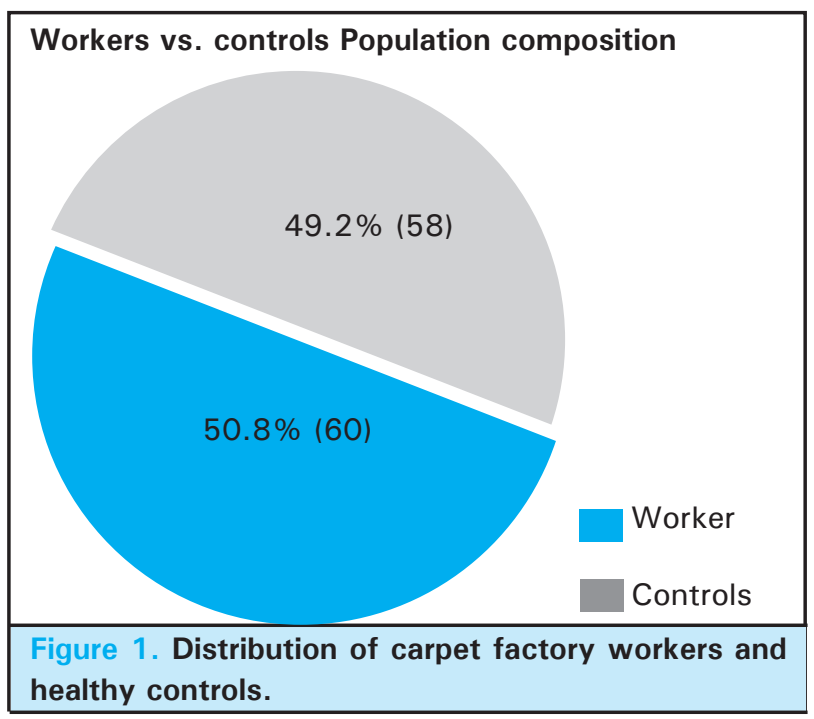


Gender Distribution of the study participants

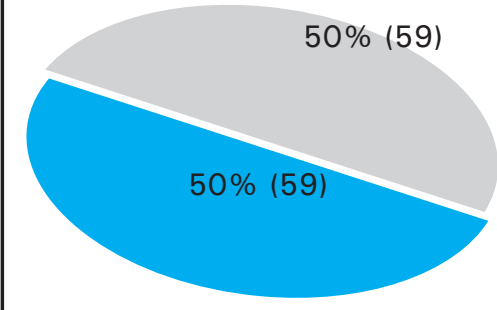

Worker

Controls

Figure 2. Distribution of male and female participants.

Pulmonary functions: Carpet factory workers vs healthy controls

The carpet factory workers had significantly less FEV $(90.37 \pm 16.6 \%$ vs. $103.89 \pm 9.79 \%, p<0.001)$, less FVC $(87.78 \pm 15.48 \%$ vs. $102.81 \pm 8.41 \%, p<$ $0.001)$ and also significantly less PEFR (66.19 \pm 20.29 $\%$ vs. $102.81 \pm 11.09 \%, p<0.001$ ) as compared to control (Figure 3 ). Similarly the carpet factory workers had significantly more $\mathrm{FEV}_{1} / \mathrm{FVC}$ ratio as compared to control $(89.96 \pm 6.42 \%$ vs. $87.12 \pm 4.58 \%, p=$ 0.007).

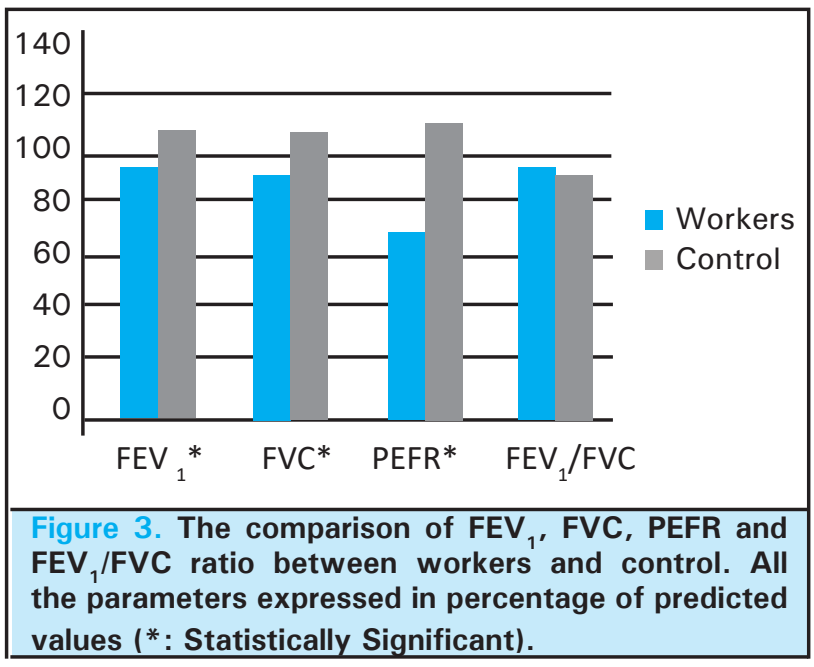

Abbreviations: FEV, $=$ Forced Expiratory Volume in First Second, FVC $=$ Forced Vital Capacity, PEFR = Peak Expiratory Flow Rate, FEV $/$ FVC $=$ Ratio of Forced Expiratory Volume in First Second and Forced Vital Capacity

Pulmonary functions: Sex-matched comparisons The male carpet factory workers had significantly deteriorated FVC $(92.73 \pm 16.94 \%$ vs. $102.89 \pm$ 10.96, $p=0.007)$ and PEFR (80.17 $\pm 13.87 \%$ vs. $109.3 \pm 13.01 \%, p<0.001)$ as compared to the sex-matched controls (Figure 4) whereas although $\mathrm{FEV}_{1}$ reduced among workers, it was not statistically significant $(98.84 \pm 16.51 \%$ vs. $103.39 \pm 12.45 \%$, $\mathrm{p}=0.238$ ). Similarly, male carpet factory workers also had a significantly raised $\mathrm{FEV}_{1} / \mathrm{FVC}$ ratio as compared to control $(92.62 \pm 5.61 \%$ vs. $85.97 \pm 5.40 \%$, p < 0.001 ) as shown in Figure 4. Similar trends (significantly reduced FVC, PEFR and also $F_{1} V_{1}$ ) was found female carpet factory workers except in case of $\mathrm{FEV}_{1} / \mathrm{FVC}$ ratio which trended to be less but not statistically significant $(87.30 \pm 6.15 \%$ vs. $88.27 \pm 3.29 \%, p=0.457)$ as compared to control (Figure 5).
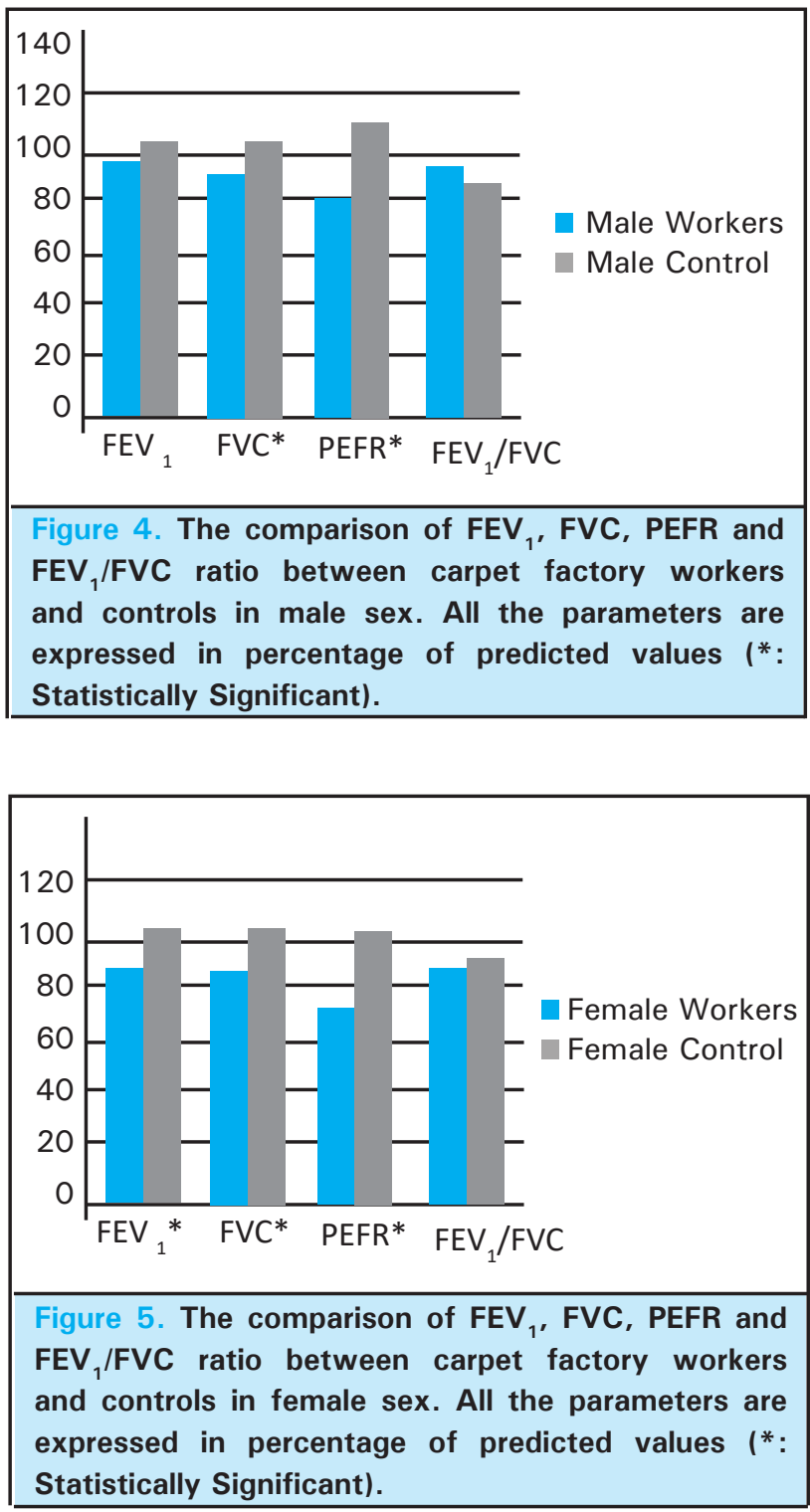

Pulmonary function parameters: Age-matched comparisons

For the age-matched comparisons, the participants were categorized four age groups as (18 -23) years, (24-28) years, (29-33) years and (34-38) years. In an age group of 18 - 23 years, FEV $_{1}$ and PEFR were found significantly decreased among workers as compared to the age-matched controls as shown in Table 1. The FVC ( $p=0.047)$ and $\mathrm{FEV}_{1} / \mathrm{FVC}$ ratio $(\mathrm{p}=0.201)$ trended to decrease but not statistically significant (Table 1). In an age group of 24-28 years; FEV ${ }_{1}, F V C$ and PEFR 
decreased significantly among workers but $\mathrm{FEV}_{1} / \mathrm{FVC}$ trended to increase ( $p=0.706)$ but not statistically significant (Table 2). There were significantly decrease in all the PFT parameters FEV, FVC, PEFR and FEV $/$ /FVC among the age group of 29-33 years as compared to the age-matched controls (Table 3 ). It was significantly decrease in FVC and PEFR while FEV 1 decreased near significant ( $p=0.050$ ) while $\mathrm{FEV}_{1} / \mathrm{FVC}$ trended to decrease but not significantly (Table 4 ) in the age group of 34-38 years.

\begin{tabular}{|c|c|c|c|c|}
\hline & $\begin{array}{l}\text { Workers/ } \\
\text { Controls }\end{array}$ & Number & Mean \pm SD & $\begin{array}{c}\mathrm{P} \\
\text { value }\end{array}$ \\
\hline \multirow{2}{*}{$\mathrm{FEV}_{1}$} & Controls & 6 & $115.01 \pm 14.78$ & \multirow[t]{2}{*}{0.020} \\
\hline & Workers & 25 & $97.93 \pm 15.28$ & \\
\hline \multirow{2}{*}{ FVC } & Controls & 6 & $108.48 \pm 11.48$ & \multirow[t]{2}{*}{0.047} \\
\hline & Workers & 25 & $94.59 \pm 15.28$ & \\
\hline \multirow{2}{*}{ PEFR } & Controls & 6 & $104.43 \pm 19.05$ & \multirow[t]{2}{*}{0.000} \\
\hline & Workers & 25 & $67.95 \pm 20.72$ & \\
\hline \multirow{2}{*}{$\begin{array}{l}\mathrm{FEV}_{1} / \\
\text { FVC }\end{array}$} & Controls & 6 & $108.68 \pm 5.36$ & \multirow[t]{2}{*}{0.201} \\
\hline & Workers & 25 & $103.93 \pm 8.43$ & \\
\hline
\end{tabular}

\begin{tabular}{|c|c|c|c|c|}
\hline & $\begin{array}{l}\text { Workers/ } \\
\text { Controls }\end{array}$ & Number & Mean $\pm S D$ & $\begin{array}{c}\mathrm{P} \\
\text { value }\end{array}$ \\
\hline \multirow{2}{*}{$\mathrm{FEV}_{1}$} & Controls & 24 & $104.46 \pm 8.95$ & \multirow[t]{2}{*}{0.000} \\
\hline & Workers & 20 & $86.92 \pm 14.74$ & \\
\hline \multirow{2}{*}{ FVC } & Controls & 24 & $104.37 \pm 8.66$ & \multirow[t]{2}{*}{0.000} \\
\hline & Workers & 20 & $83.43 \pm 13.31$ & \\
\hline \multirow{2}{*}{ PEFR } & Controls & 24 & $103.12 \pm 7.96$ & \multirow[t]{2}{*}{0.000} \\
\hline & Workers & 20 & $65.67 \pm 18.56$ & \\
\hline \multirow{2}{*}{$\begin{array}{l}\text { FEV }_{1} / \\
\text { FVC }\end{array}$} & Controls & 24 & $103.57 \pm 5.65$ & \multirow[t]{2}{*}{0.706} \\
\hline & Workers & 20 & $104.27 \pm 6.56$ & \\
\hline
\end{tabular}

\begin{tabular}{|c|c|c|c|c|}
\hline & $\begin{array}{l}\text { Workers/ } \\
\text { Controls }\end{array}$ & Number & Mean \pm SD & $P$ value \\
\hline \multirow{2}{*}{$\mathrm{FEV}_{1}$} & Controls & 20 & $100.22 \pm 6.32$ & 0.000 \\
\hline & Workers & 10 & $79.81 \pm 18.06$ & \\
\hline \multirow{2}{*}{ FVC } & Controls & 20 & $99.50 \pm 5.29$ & 0.000 \\
\hline & Workers & 10 & $81.15 \pm 15.05$ & \\
\hline \multirow{2}{*}{ PEFR } & Controls & 20 & $106.65 \pm 8.90$ & 0.000 \\
\hline & Workers & 10 & $56.53 \pm 24.72$ & \\
\hline $\mathrm{FEV}_{1} /$ & Controls & 20 & $105.65 \pm 4.31$ & 0.001 \\
\hline FVC & Workers & 10 & $97.70 \pm 7.34$ & \\
\hline
\end{tabular}

\begin{tabular}{|llccc|}
\hline $\begin{array}{l}\text { Table 4. PFT comparisons in the age group of 34-38 } \\
\text { years. }\end{array}$ \\
\hline \multirow{6}{*}{ FEV $_{1}$} & $\begin{array}{l}\text { Workers/ } \\
\text { Controls }\end{array}$ & Number & Mean \pm SD & P value \\
& Controls & 8 & $103.00 \pm 10.35$ & 0.050 \\
FVC & Corkers & 5 & $87.49 \pm 15.29$ & \\
& Wontrols & 8 & $102.20 \pm 7.49$ & 0.021 \\
PEFR & Controls & 8 & $114.77 \pm 14.11$ & 0.000 \\
& Workers & 5 & $78.86 \pm 5.90$ & \\
FEV ${ }_{1} /$ & Controls & 8 & $105.06 \pm 3.51$ & 0.711 \\
FVC & Workers & 5 & $104.05 \pm 6.16$ & \\
\hline
\end{tabular}

\section{DISCUSSION}

The major finding of the study is that the carpet industry generated air pollution (dust, dyes and continuous exposure) impairs the pulmonary functions of the workers. Here, we report that there is statistically significant deterioration of FEV ${ }_{1}, F V C$ and PEFR among carpet industry workers as compared to the age and sex matched controls. There is significantly elevated $\mathrm{FEV}_{1} / \mathrm{FVC}$ ratio among the workers than controls.

Our findings of significant reductions in important pulmonary function parameters (FEV $1, F V C$, and PEFR) are consistent with past studies. ${ }^{12,26}$ We also found that there is significantly elevated $\mathrm{FEV}_{1} / \mathrm{FVC}$ ratio among workers as compared to the controls. ${ }^{27} \mathrm{We}$ have tried to match the control groups in both age and sex distributions (a total of 118 subjects: $50.8 \%$ and $49.2 \%$ controls where as $50 \%$ male and $50 \%$ female). On sex-matched comparisons with the controls, FVC and PEFR were significantly reduced among workers but FEV 1 was lower although it was not statistically significant. Whereas the ratio of $\mathrm{FEV}_{1} / \mathrm{FVC}$ was more among workers group than the control group and the difference was statistically significant. In females it was found that all the parameters FEV ${ }_{1}, F V C$ and PEFR were significantly reduced but $F E V_{1} / F V C$ just trended to be less but not statistically significant as compared to control. Because the measurement of PEFR is dependent on effort and technique, subjects need instructions, demonstrations, and frequent reviews of technique. The explanation for the significant difference in the PEFR may be faulty technique and less effort among the workers.

Rastogi et al had reported similar results in a study done among 274 workers and 54 controls in India. ${ }^{28}$ In a study done Das and Jha among jute mill workers in Nepal $(95$ male workers who had been working at least one year or more) report that there was a significant reduction in $\mathrm{FEV}_{1}, \mathrm{FVC}$, and PEFR whereas no significant reduction in $\mathrm{FEV}_{1} / \mathrm{FVC}$ ratio. 
Symptomatically, byssinosis is a common condition due to exposure of cotton, flax, linen, and rope making dusts similar exposure to carpet industry. ${ }^{29-31}$ There is occasional chest tightness in early stage and then regularly in late stages toward the end of the first day of the work week commonly known as "Monday chest tightness". In epidemiologic studies, depending on the level of exposure, up to $80 \%$ of employees may show a significant drop in their FEV 1 over the course. ${ }^{28} 32$ Our findings corroborate these literatures but we did not find any symptoms like that of 'Monday chest tightness' which might be related to the duration of years workers have been exposed. ${ }^{7}$ We have included workers who have worked more than a year but the past studies have included workers who have been working for years.

When the age ranges were split up and compared with their age-matched controls, the findings were mixed. In an age group of 18 - 23 years (where control group was small), FEV 1 and PEFR were found significantly decreased among workers as compared to the agematched controls. The FVC and $\mathrm{FEV}_{1} / \mathrm{FVC}$ ratio (18 - 23 years) trended to decrease but not statistically significant. Similar findings were found in the age group of 24-28 years whereas $\mathrm{FEV}_{1} / \mathrm{FVC}$ trended to increase but not statistically significant. The group of 29-33 years seems to have been most affected with the decrease in all the PFT parameters $\left(F^{2} V_{1}, F V C\right.$, PEFR and $F E V_{1} / F V C$ ) as compared to their age-matched controls. There were matched numbers but small group in the age group of 34-38 years in which FVC and PEFR were decreased while $\mathrm{FEV}_{1}$ decreased near significant ( $p=0.050$ ) while $\mathrm{FEV}_{1} / \mathrm{FVC}$ trended to decrease but not significantly. The heterogeneity of findings among the age-range groups could be due to their duration of work (exposure) ${ }^{7}$ which was not quantified here. ${ }^{33}$ Secondly, it could be due to small size in the respective ranges (both in workers versus controls). 7,14,32 Third, it may be due to their past history of exposure to other factors for example, indoor pollution, passive smoking ${ }^{34}$ or other occupational exposures. ${ }^{35-37}$ But overall trend in whole sample analysis, there is decrease in $\mathrm{FEV}_{1}, \mathrm{FVC}$, PEFR and increase in FEV 1 /FVC ratio among workers as compared to controls.

Therefore, working in carpet factory for at least one year is associated with impairment in pulmonary function testing. Decrease in $\mathrm{FEV}_{1}$ and increase in $\mathrm{FEV}_{1} / \mathrm{FVC}$ ratio points towards both obstructive and restrictive lung diseases.

\section{CONCLUSIONS}

Carpet industry dusts exposure impairs the lung function of the employees as compared to the age and sex matched controls. There is significant reduction in pulmonary function parameters e.g. FEV ${ }_{1}$, FVC and PEFR and elevation of $F_{1} V_{1} / F V C$ ratio. The $F E V_{1}, F V C$ and PEFR are reduced in all age groups as compared to agematched controls while $\mathrm{FEV}_{1} / \mathrm{FVC}$ ratio is significantly raised only in 29-33 age groups. Pulmonary function tests seem useful in early detection of lung function deterioration among carpet factory workers and could be useful for the prevention of such conditions.

\section{Limitations and Recommendations}

Present study employed a cross-sectional comparative method to see the effects of one or more exposure to the carpet dust among the carpet industry workers. It is important to look into the prospective time dependent effect of exposure as well as the symptomatic effects or manifestations. Hence, future studies should focus on that direction. At the same time, there are simultaneous exposure of dusts, poor ventilation, crowded environment and dyes. Hence, there could be other associated health effects that would be beneficial to incorporate. Hence, further studies with physical examination, chest radiograph and pulmonary function testing before and after the work shift on the first day of week is necessary.

\section{ACKNOWLEDGEMENTS}

We would like to express our sincere thanks to the study participants and carpet industry workers for their immense support on agreeing to participate on the study. We would like thank our colleagues from The Department of Clinical Physiology, Maharajgunj Medical Campus, Institute of Medicine. Finally, we would also like to thank IRB of IOM for the ethical approval to conduct this study. Authors would like to acknowledge Dr Amod Dhungana, MD who had major contribution during study design, data collection and interpretation. Sadly, Dr Dhungana was unable to contribute during manuscript preparation, editing, review and submission processes. Dr Dhungana is unable to respond to the editors and reviewers.

\section{REFERENCES}

1. Rastogi SK, Gupta BN, Husain T, Mathur N. Respiratory health effects from occupational exposure to wood dust in sawmills. American Industrial Hygiene Association journal 1989;50:574-8.
2. Mathur N, Rastogi SK. Respiratory effects due to occupational exposure to formaldehyde: Systematic review with meta-analysis. Indian J Occup Environ Med 2007;11:26-31. 
3. CCIA. A complete information about carpet industries of Nepal (CCIA). Online. 2015 ed. Nepal: Central Carpet Industries Association; 2015.

4. Paudyal P, Ayres JG, Semple S, Macfarlane GJ. Low back pain among textile workers: a cross-sectional study. Occupational Medicine 2013;63:129-34.

5. Macdonald W, Oakman J. Requirements for more effective prevention of work-related musculoskeletal disorders. BMC Musculoskeletal Disorders 2015;16:293.

6. Rylander R. Health effects of cotton dust exposures. American journal of industrial medicine 1990;17:39-45.

7. Wang XR, Eisen EA, Zhang HX, et al. Respiratory symptoms and cotton dust exposure; results of a 15 year follow up observation. Occupational and environmental medicine 2003;60:935-41.

8. Wani KA, Jaiswal YK. Health risk factors in different seasons of carpet industry in Kashmir, India. International journal of occupational safety and ergonomics : JOSE 2012;18:571-7.

9. Choobineh A, Shahnavaz H, Lahmi M. Major health risk factors in Iranian hand-woven carpet industry. International journal of occupational safety and ergonomics : JOSE 2004;10:65-78.

10. Subedi RK, Banamala S. Occupational Safety and Health among Carpet Factory Workers in a District of Nepal. Open Access Library Journal 2015;2:1-9.

11. Rao NM, Kashyap SK, Kulkarni PK, Saiyed HN, Purohit AK, Patel BD. Pulmonary function studies in 15 to 18 years age workers exposed to dust in industry. Indian journal of physiology and pharmacology 1992;36:51-4.

12. Salmani Nodoushan M, Mehrparvar AH, Loukzadeh Z, Rahimian M, Ghove Nodoushan MA, Jafari Nodoushan R. Evaluation of respiratory system in textile-dyeing workers. Medical journal of the Islamic Republic of Iran 2014;28:88.

13. WHO. Reducing Workplace Exposure throughout Risk Management Toolkit, Report of the Regional Consultant Chennai, India. Chennai, India: World Health Organization (WHO); 2004, 2006 and 2007.

14. Xiang J, Bi P, Pisaniello D, Hansen A. Health impacts of workplace heat exposure: an epidemiological review. Industrial health 2014;52:91-101.

15. Lai PS, Christiani DC. Long-term respiratory health effects in textile workers. Current opinion in pulmonary medicine 2013;19:152-7.

16. Dela Cruz CS, Tanoue LT, Matthay RA. Lung cancer: epidemiology, etiology, and prevention. Clinics in chest medicine 2011;32:605-44.

17. McCarthy WJ, Meza R, Jeon J, Moolgavkar SH. Lung cancer in never smokers: epidemiology and risk prediction models. Risk analysis : an official publication of the Society for Risk Analysis 2012;32 Suppl 1:S69-84.

18. Christiani DC, Wang XR. Respiratory effects of long-term exposure to cotton dust. Current opinion in pulmonary medicine 2003;9:151-5.
19. Nair RP. The Kerala Construction Labour Welfare Fund. Geneva, Switzerland: International Labour Organization Office; 2004.

20. Paudyal P, Semple S, Gairhe S, Steiner MFC, Niven R, Ayres JG. Respiratory symptoms and cross-shift lung function in relation to cotton dust and endotoxin exposure in textile workers in Nepal: a cross-sectional study. Occupational and environmental medicine 2015 .

21. Paudyal P, Semple S, Niven R, Tavernier G, Ayres JG. Exposure to Dust and Endotoxin in Textile Processing Workers. Annals of Occupational Hygiene 2011;55:403-9.

22. Bency KT, Jansy J, Thakappan B, Kumar B, Sreelekha TT. A Study on the Air Pollution related Human Diseases in Thiruvananthapuram City, Kerala. Third International Conference on Environment and Health, Chennai, India2003:15-22.

23. MIR. Spirolab II. Via del Maggiolino, 12500155 Roma, Italy: Medical International Research (MIR); 2008.

24. Hankinson JL, Bang KM. Acceptability and Reproducibility Criteria of the American Thoracic Society as Observed in a Sample of the General Population. American Review of Respiratory Disease 1991;143:516-21.

25. Enright PL, Beck KC, Sherrill DL. Repeatability of Spirometry in 18,000 Adult Patients. American journal of respiratory and critical care medicine 2004;169:235-8.

26. Das PKL, Nepal GB, Upadhyay-Dhungel K, Panta R, Bhaila A, Shakya B. Occupational Exposure and Pulmonary Function of Workers of Carpet Industries and Sawmills, Lalitpur, Nepal. Asian Journal of Medical Sciences 2014;5:54-8.

27. Ghosh T, Gangopadhyay S, Das B. Prevalence of respiratory symptoms and disorders among rice mill workers in India. Environmental health and preventive medicine 2014;19:226-33.

28. S.K. R, I. A, B.S.and P. Effects of Occupational Exposure on Respiratory System in Carpet Workers. Indian Journal of Occupational and Environmental Medicine 2003.

29. Murlidhar V, Murlidhar VJ, Kanhere V. Byssinosis in a Bombay textile mill. The National medical journal of India 1995;8:204-7.

30. Mohammadien HA, Hussein MT, El-Sokkary RT. Effects of exposure to flour dust on respiratory symptoms and pulmonary function of mill workers. Egyptian Journal of Chest Diseases and Tuberculosis 2013;62:745-53.

31. Johncy SS, G D, Samuel TV, K TA, Bondade SY. Acute lung function response to dust in street sweepers. Journal of clinical and diagnostic research : JCDR 2013;7:2126-9.

32. Christiani DC, Wang XR, Pan LD, et al. Longitudinal changes in pulmonary function and respiratory symptoms in cotton textile workers. A 15-yr follow-up study. American journal of respiratory and critical care medicine 2001;163:847-53.

33. Weiss ST. Lung function and airway diseases. Nat Genet 2010;42:14-6. 
34. Baena-Cagnani CE, Gomez RM, Baena-Cagnani R, Canonica GW. Impact of environmental tobacco smoke and active tobacco smoking on the development and outcomes of asthma and rhinitis. Current opinion in allergy and clinical immunology 2009;9:136-40.

35. Pacheco SA, Torres VM, Louro H, et al. Effects of occupational exposure to tobacco smoke: is there a link between environmental exposure and disease? Journal of toxicology and environmental health Part A 2013;76:311-27.
36. Cuijpers CE, Swaen GM, Wesseling G, Sturmans F, Wouters EF. Adverse effects of the indoor environment on respiratory health in primary school children. Environmental research 1995;68:11-23.

37. Janson C. The effect of passive smoking on respiratory health in children and adults. The international journal of tuberculosis and lung disease : the official journal of the International Union against Tuberculosis and Lung Disease 2004;8:510-6. 